\title{
Comparing the effect of clopidogrel versus ticagrelor on coronary microvascular dysfunction in acute coronary syndrome patients (TIME trial): study protocol for a randomized controlled trial
}

\author{
Sang-Don Park ${ }^{\dagger}$, Yong-Soo Baek', Seong-III Woo, Soo-Han Kim, Sung-Hee Shin, Dae-Hyeok Kim*, Jun Kwan \\ and Keum-Soo Park
}

\begin{abstract}
Background: Although prompt reperfusion treatment restores normal epicardial flow, microvascular dysfunction may persist in some patients with acute coronary syndrome (ACS). Impaired myocardial perfusion is caused by intraluminal platelets, fibrin thrombi and neutrophil plugging; antiplatelet agents play a significant role in terms of protecting against thrombus microembolization. A novel antiplatelet agent, ticagrelor, is a non-thienopyridine, direct P2Y12 blocker that has shown greater, more rapid and more consistent platelet inhibition than clopidogrel. However, the effects of ticagrelor on the prevention of microvascular dysfunction are uncertain. The present study is a comparison between clopidogrel and ticagrelor use for preventing microvascular dysfunction in patients with ST elevation or non-ST elevation myocardial infarction (STEMI or NSTEMI, respectively).

Methods/design: The TIME trial is a single-center, randomized, open-label, parallel-arm study designed to demonstrate the superiority of ticagrelor over clopidogrel. A total of 152 patients with a spectrum of STEMI Or NSTEMI will undergo prospective random assignment to clopidogrel or ticagrelor (1:1 ratio). The primary endpoint is an index of microcirculatory resistance (IMR) measured after percutaneous coronary intervention (PCI); the secondary endpoint is wall motion score index assessed at 3 months by using echocardiography.
\end{abstract}

Discussion: The TIME trial is the first study designed to compare the protective effect of clopidogrel and ticagrelor on coronary microvascular dysfunction in patients with STEMI and NSTEMI.

Trial registration: ClinicalTrials.gov: NCT02026219. Registration date: 24 December 2013.

Keywords: MeSH terms, Myocardial infarction, Antiplatelet agents, Microcirculation

\section{Background}

The novel antiplatelet agents, prasugrel and ticagrelor, have overcome many of the pharmacodynamic limitations of clopidogrel and have improved outcomes in patients with acute coronary syndrome (ACS) [1,2].

Ticagrelor is a non-thienopyridine, direct P2Y12 blocker that is more potent than clopidogrel and is associated with less inter-individual variability. In the PLATO trial, it was found to be superior to clopidogrel with respect to

\footnotetext{
*Correspondence: denki1@inha.ac.kr

${ }^{\dagger}$ Equal contributors

Department of Internal Medicine, Inha University Hospital, 7-206,

3-GA Sinheung-Dong, Jung-gu, Incheon 400-711, South Korea
}

cardiovascular outcomes and total mortality without increasing the risk of bleeding [2].

Faster onset of action and more potent and reversible receptor bindings are possible explanations for the superior outcomes of ticagrelor [3]. In addition to the potent inhibition of platelet function, ticagrelor has previously been shown to increase adenosine levels by inhibiting adenosine re-uptake at the tissue level and inducing adenosine triphosphate (ATP) release from human red blood cells, which stimulate vasodilation [4]. A recent study confirmed that ticagrelor increased adenosine plasma concentration in patients with ACS when compared with clopidogrel [5]. 
Since the microvascular dysfunction is multifactorially developed, involving intraluminal platelets, fibrin thrombi, neutrophil plugging, vasoconstriction, myocyte contracture, local interstitial edema and intramural hemorrhage [6-8], antiplatelet agents have been used as a basic medication for protecting against microvascular dysfunction $[9,10]$.

However, there has been no data on the role of higher plasma adenosine and stronger inhibition of platelets in the protection against microvascular dysfunction in ST elevation or non-ST elevation myocardial infarction (STEMI or NSTEMI, respectively). Thus, we have designed a clinical study that will compare the protective effect of ticagrelor and clopidogrel on microvascular dysfunction in patients with STEMI and NSTEMI. In our study, microvascular dysfunction will be assessed by using the index of microcirculatory resistance (IMR), which correlates closely with microvascular damage in myocardial infarction [11].

\section{Methods}

\section{Study design}

The TIME trial is a single-center, randomized, open-label, parallel-arm study designed to demonstrate the superiority of ticagrelor compared with clopidogrel treatment in preventing microvascular dysfunction in patients with STEMI and NSTEMI.

The protocol of the trial has been registered at ClinicalTrials.gov (NCT02026219), and a brief flowchart of the entire study is summarized in Figure 1. The schedule of events for this trial is described in Table 1.

\section{Endpoints}

The primary endpoint of the study is an IMR measured immediately after index percutaneous coronary

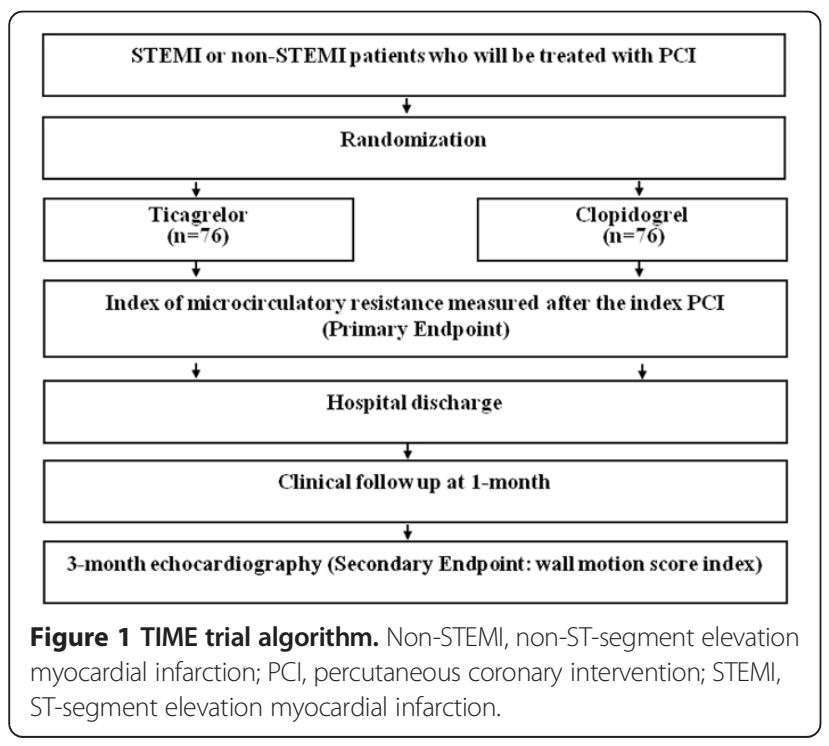

intervention (PCI). The secondary endpoint is the echocardiographic finding of left ventricular wall motion score index at 3 months after the index PCI.

\section{Patient population}

We will enroll 152 patients, comprising 76 patients in the ticagrelor group and 76 patients in the clopidogrel group. Patients of at least 18 years of age, who have STEMI or NSTEMI with documented ischemia due to a significant lesion in a native coronary artery, will be included in this study. All inclusion and exclusion criteria are summarized in Appendix A and Appendix B, respectively.

If all the inclusion criteria are met and none of the exclusion criteria apply, the patients will be asked to provide written informed consent, as required by the institutional review board and in accordance with the Declaration of Helsinki.

\section{Randomization and interventions}

After the patients are enrolled, drug randomization will be performed by using a random number table that will be independently managed at the Inha University Hospital Cardiovascular Research Center (Incheon, South Korea).

\section{Percutaneous coronary intervention ( $\mathrm{PCl})$}

After random assignment to clopidogrel or ticagrelor treatment, the index PCI procedure must be carried out on all patients within 48 hours. All patients will receive $300 \mathrm{mg}$ aspirin and a loading dose of $600 \mathrm{mg}$ clopidogrel or $180 \mathrm{mg}$ ticagrelor before the procedure, unless the patient has been taking one of these medications for at least 1 week prior to the procedure. Unfractionated heparin will be administered intravenously in boluses to maintain an activated clotting time of $>250$ seconds during the procedure. Administration of glycoprotein IIb/ IIIa inhibitors will be based on the physician's discretion. PCI will be performed according to current international guidelines. The goals of the procedure are to achieve optimal angiographic efficacy of PCI at the infarct-related artery and minimize the risk of procedure-related complications. A full range of commercially available guiding catheters, balloon catheters and guide wires will be readily available.

\section{Index of microcirculatory resistance (IMR) measurements} IMR measured at the infarct-related artery after primary PCI is a strong predictor of myocardial damage [11] and will provide a quantitative assessment of microvascular dysfunction in ACS patients [12]. We plan to assess the microvascular dysfunction using IMR measured at the infarct-related artery immediately after reperfusion therapy.

The IMR will be assessed immediately after index PCI by using methods described previously $[13,14]$. An intracoronary combined pressure-temperature sensor-tipped guide 
Table 1 Schedule of events

\begin{tabular}{|c|c|c|c|c|}
\hline \multirow[t]{3}{*}{ Variable } & \multirow[t]{3}{*}{ Baseline } & \multirow{3}{*}{$\begin{array}{c}\text { Post- } \\
\text { procedure }\end{array}$} & \multicolumn{2}{|c|}{ Follow-up } \\
\hline & & & 30 days & 3 months \\
\hline & & & \pm 2 weeks & \pm 1 month \\
\hline Medical/clinical history (age, sex, risk factors, clinical diagnosis, angina status, cardiac history) & $x$ & & & \\
\hline Informed consent ${ }^{\mathrm{a}}$ & $x$ & & & \\
\hline Inclusion/exclusion criteria & $x$ & & & \\
\hline Brief physical examination & $x$ & & & \\
\hline Vital status & $x$ & & $x$ & $x$ \\
\hline Weight, height & $x$ & & & \\
\hline 12-lead ECG & $x$ & $x$ & & $x$ \\
\hline Angiogram ${ }^{c}$ & $x$ & & & \\
\hline IMR examination & & $x$ & & \\
\hline CBC & $x$ & & & $x$ \\
\hline Electrolytes, LFT & $x$ & & & $x$ \\
\hline Creatinine, BUN & $x$ & & & $x$ \\
\hline hs-CRP & $x$ & & & $x$ \\
\hline Fasting plasma triglycerides, HDL cholesterol, total cholesterol & $x$ & & & $x$ \\
\hline Fasting glucose level $^{d}$ & $x$ & & & $x$ \\
\hline $\mathrm{HbA} 1 c^{\mathrm{e}}$ & $x$ & & & $x$ \\
\hline Medications & $x$ & & $x$ & $x$ \\
\hline$C K, C K-M B$, troponin $I^{f}$ & $x$ & $x$ & & \\
\hline proBNP & $x$ & & & $x$ \\
\hline Echocardiography & $x$ & & & $x$ \\
\hline
\end{tabular}

${ }^{a}$ The informed consent will be signed either prior to or after the diagnostic angiogram; ${ }^{b}$ additional ECGs will be performed at $60 \pm 30$ minutes post-procedure. ECG at follow-up visits will only be obtained when clinically indicated by symptoms such as recurrent chest pain, ischemia or significant arrhythmias, heart failure

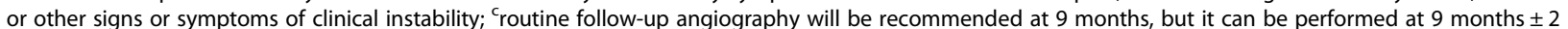
months. Unscheduled angiograms $\geq 6$ months after index procedure will be considered as the 9-month follow-up angiogram in final analysis; ${ }^{d}$ might be measured later, before discharge, when the patient is in a fasting state; ${ }^{e}$ will be performed in patients with diagnosed diabetes mellitus; ${ }^{f}$ cardiac enzyme levels should be followed up for at least 24 hours in patients with symptoms such as recurrent chest pain, ischemia, significant arrhythmias, heart failure or other clinical signs or symptoms of cardiac instability. Otherwise, the decision is up to the operator. If follow-up is performed, enzyme levels must be measured every 8 hours for at least 24 hours post-index procedure. BUN, blood urea nitrogen; CBC, complete blood count; CK, creatine kinase; ECG, electrocardiogram; HbA1c, hemoglobin A1c; HDL, high-density lipoprotein; hs-CRP, high sensitivity C-reactive protein; IMR, index of microcirculatory resistance; LFT, liver function test; pro-BNP, pro-brain natriuretic peptide.

wire (Radi PressureWire 5; Radi Medical Systems, Uppsala, Sweden) will be used to measure the thermodilutionderived IMR and fractional flow reserve (FFR). The pressure sensor will be placed at the distal two-thirds of the infarct-related artery. Intracoronary nitroglycerine will be administered $(200 \mu \mathrm{g})$. Hyperemia will be induced by using an adenosine infusion $(140 \mu \mathrm{g} / \mathrm{kg} \cdot \mathrm{min})$ administered via the femoral or antecubital vein. Aortic and distal coronary pressures will be measured during hyperemia, and the FFR will be calculated by using the formula: FFR $=$ Distal coronary pressure/Aortic pressure. The IMR will be calculated from the ratio of the mean distal coronary pressure at maximal hyperemia to the inverse of the hyperemic mean transit time $\left(T_{\mathrm{mn}}\right)$ as follows: IMR $=$ Distal pressure $\times T_{\mathrm{mn}}$ during hyperemia [13,15]. Vessels with severe stenosis (distal coronary pressure $\leq 60 \mathrm{mmHg}$ ) and collateral flow will be excluded from the analysis because of the effect of collateral flow $[16,17]$.

\section{Post-PCl medication}

All patients included in this trial will be treated according to the current American College of Cardiology (ACC)/ American Heart Association (AHA) guidelines regarding post-stenting management, which specify treatment with at least $100 \mathrm{mg}$ of aspirin daily, and $75 \mathrm{mg}$ clopidogrel or $90 \mathrm{mg}$ ticagrelor daily for at least 12 months after PCI.

\section{Follow-up}

Clinical follow-up will be performed at specified time points (Table 1). Follow-ups should be office visits, but telephone contact will be allowed. Data collected during all follow-up visits will include angina class and the presence of major adverse ischemic, neurologic or bleeding events, including re-hospitalization, re-catheterization and adverse events/serious adverse events (SAEs). Original source documents must be submitted for any clinical events (death, reinfarction, revascularization, stroke or any 
other SAE within the 9-month follow-up). If the patient is readmitted to a non-study hospital, all possible efforts should be made to obtain original source documents from that hospital. For all reinfarctions, ECGs and cardiac enzymes (creatine kinase (CK), CK-MB and troponin) must be obtained and recorded.

\section{Sample size calculation}

The objective is to determine whether ticagrelor is superior to clopidogrel in preventing microvascular dysfunction in patients with STEMI or NSTEMI. Based on previous reports for IMR values in STEMI and NSTEMI $[11,18,19]$, we will assume that the mean IMR in the clopidogrel group is approximately $30 \mathrm{U}$ with a standard deviation of $20 \mathrm{U}$. To demonstrate that ticagrelor is superior to clopidogrel, we will assume a reduction in IMR of more than $10 \mathrm{U}$. Taking into account a drop-out rate of $20 \%$ of the randomized patients, we will need 152 patients, comprising 76 in the ticagrelor group and 76 in the clopidogrel group, with $80 \%$ power to detect a group difference of $10 \mathrm{U}$ in the change of the IMR value at a two-sided alpha-level of 0.05 .

\section{Statistical analyses}

All primary and secondary endpoints will be analyzed both on an intention-to-treat basis (all patients analyzed as part of their assigned treatment group) and on a per protocol basis (patients analyzed as part of their assigned treatment group only if they actually received their assigned treatment).

Multivariate predictors of all primary and secondary endpoints will be determined by using multivariate regression models. Forward stepwise selection algorithms will be used to select independent predictors. Baseline characteristics of study patients will be summarized in terms of frequencies and percentages for categorical variables and by using means with standard deviations for continuous variables. Categorical variables will be compared by using Fisher's exact test. Continuous variables will be compared by using the two-sample $t$-test. A $P$ value of 0.05 will be established as the level of statistical significance for all tests. Major subgroup analyses of the primary and major secondary endpoints will be performed, including patients with diabetes mellitus, advanced age (age $\geq 70$ years) and the diagnosis (STEMI or NSTEMI).

\section{Trial organization}

\section{Executive committee}

The executive committee will comprise the study chairperson and the principal investigators of the investigating center. This committee will approve the final trial design and protocol that will be issued to the Data and Safety Monitoring Board (DSMB) and the clinical site. This committee will also be responsible for reviewing the final results, determining the methods of presentation and publication, and the selection of secondary projects and publications by members of the steering committee.

\section{Data Safety Monitoring Board (DSMB)}

The DSMB is composed of general and interventional cardiologists. The DSMB will function in accordance with applicable regulatory guidelines. The board members are independent and will not be participating in the trial. The DSMB committee will review the safety data from this study, and make recommendations based on safety analyses of unanticipated device effects, SAEs, protocol deviation, device failures and 30-day follow-up reports. The frequency of the DSMB meetings will be determined prior to study commencement. Additionally, the DSMB may call a meeting at any time if there is reason to suspect that safety is an issue.

All cumulative safety data will be reported to the DSMB and reviewed on an ongoing basis throughout enrollment and follow-up periods to ensure patient safety. Every effort will be made to allow the DSMB to conduct an unbiased review of patient safety information. All DSMB reports will be made available to the appropriate agencies upon request but will otherwise remain strictly confidential.

\section{Clinical events adjudication committee (CEAC)}

The clinical events adjudication committee (CEAC) is comprised of interventional and non-interventional cardiologists who are not participants in the study. The CEAC is charged with the development of specific criteria to be used for the categorization of clinical events and clinical endpoints in the study, which are based on protocol. At the outset of the trial, the CEAC will establish explicit rules outlining the minimum amount of dates required and the algorithm to be followed in order to classify a clinical event. All members of the CEAC will be blinded to the primary results of the trial.

The CEAC will meet regularly to review and adjudicate all clinical events in which the required minimum data is available. The Committee will also review and rule on all deaths that occur throughout the trial.

\section{Ethical approval}

This study has been approved by the institutional review board of Inha University Hospital.

\section{Discussion}

Although prompt reperfusion treatment restores normal epicardial flow, microvascular dysfunction may persist in some patients with ACS [20,21]. The presence of microvascular dysfunction is considered a poor prognostic factor in patients with ACS [22-24].

Impaired myocardial perfusion is caused by intraluminal platelets, fibrin thrombi, neutrophil plugging, 
vasoconstriction, myocyte contracture, local interstitial edema and intramural hemorrhage [6-8]. There have been a number of studies in patients with ACS in which the use of antiplatelet agents and vasodilators attenuated myocardial damage [9,10,25-28]. Such findings strongly support the contribution of thrombotic and vasoconstrictor mechanisms leading to the development of impaired microcirculation. Antiplatelet agents play a relevant role in protecting against thrombus microembolization.

Recently the novel antiplatelet agents, ticagrelor and prasugrel, have exhibited greater, more rapid and more consistent platelet inhibition than clopidogrel. Ticagrelor is a non-thienopyridine, direct P2Y12 blocker that is more potent than clopidogrel and is associated with less inter-individual variability. In the PLATO trial, ticagrelor was found to be superior to clopidogrel with respect to cardiovascular outcomes and total mortality without increasing the risk of bleeding [2].

The dual antiplatelet regimen including aspirin and clopidogrel has been used as the standard antiplatelet modality in patients with ACS; however, clopidogrel has several negative features. For example, the phenomenon of the variability of response to clopidogrel, causing elevated platelet reactivity, is seen in approximately 15 to $30 \%$ of patients, and it has been linked to ischemic events including stent thrombosis after PCI. Another issue is the delayed onset of action [29-31] that may be observed with clopidogrel treatment. These drawbacks have led to the development of more potent and rapid-acting antiplatelet agents. Compared with clopidogrel, ticagrelor causes greater, faster and more consistent platelet inhibition [2].

Beside the potent effect of inhibition of platelet function, ticagrelor has been demonstrated previously to increase adenosine levels by inhibiting adenosine re-uptake at the tissue level and inducing ATP release from human red blood cells, which stimulate vasodilation [4]. In addition, a recent in vivo study in patients with ACS showed a significant increase in adenosine plasma concentration in patients treated with ticagrelor. In previous studies, adenosine has shown multiple mechanisms affecting platelet function, vessel tone and microcirculation. Adenosine inhibits platelet aggregation through the activation of adenosine $2 \mathrm{~A}$ receptors and also dilates coronary microvessels through the activation of adenosine $2 \mathrm{~A}$ receptors, which are strongly implicated in the regulation of coronary blood flow [32,33]. However, the role of adenosine in protecting the ischemic heart remains controversial and the long-term impact of high plasma adenosine concentration on coronary artery disease remains to be determined [34]. These properties of adenosine may be particularly important in the context of diseased vessels and the ischemia associated with ACS.

Consequently, based on the potent antiplatelet effect and pleiotropic properties mediated by the increased adenosine, we postulate that ticagrelor will reduce the microvascular dysfunction in patients with ACS compared with clopidogrel. Therefore, we designed a clinical study that will evaluate the protective effect on microvascular dysfunction of ticagrelor compared with clopidogrel in patients with STEMI and NSTEMI.

\section{Trial status}

Enrollment into the TIME trial started in September 2013. The study is expected to be completed by the end of August 2014.

\section{Appendix A}

Inclusion criteria:

- Patients with STEMI or NSTEMI with documented ischemia due to a significant lesion in a native coronary artery

- Patients eligible for coronary revascularization through PCI

- Patients must be $\geq 18$ years of age

- Patients who are mentally and linguistically able to understand the aim of the study and show sufficient compliance in following the study protocol

- Patients are able to verbally acknowledge an understanding of the associated risks, benefits and treatment alternatives to therapeutic options of this trial. The patients, by providing informed consent, agree to these risks and benefits as stated in the patient informed consent document.

\section{Appendix B}

Exclusion criteria:

- Unprotected left main artery

- Culprit lesion at side branch

- Stent thrombosis

- High-degree atrioventricular block

- Cardiogenic shock

- Cardiac arrest

- Contraindication to adenosine

- Pregnancy

- History of cerebrovascular accident or myocardial infarction within 1 year.

\section{Abbreviations}

ACC: American College of Cardiology; ACS: Acute coronary syndrome; AHA: American Heart Association; ATP: Adenosine triphosphate; CEAC: Clinical events adjudication committee; CK: Creatine kinase; DSMB: Data and Safety Monitoring Board; FFR: Fractional flow reserve; IMR: Index of microcirculatory resistance; NSTEMI: ST-segment non-elevation myocardial infarction; PCl: Percutaneous coronary intervention; SAE: Serious adverse event; STEMI: ST-segment elevation myocardial infarction.

Competing interests

The authors declare that they have no competing interests. 


\section{Authors' contributions}

SD and YS conceived the work, undertook data collection and analysis, and wrote the manuscript. DH and SHS designed the work and critically revised the manuscript. SI and SHK undertook data collection and analysis. JK and KS designed the work, undertook data collection, and critically revised the manuscript. All authors read and approved the final manuscript.

\section{Acknowledgements}

We are grateful to the numerous colleagues who provided clinical and research support in treating and following the patients included in this trial. This work was not supported by any external funding

Received: 25 January 2014 Accepted: 16 April 2014

Published: 1 May 2014

\section{References}

1. Sosnowski C: Commentary to the article: Wiviott SD, Braunwald E, McCabe CH, Montalescot G, Ruzyllo W, Gottlieb S, Neumann FJ, Ardissino D, De Servi S, Murphy SA, Riesmeyer J, Weerakkody G, Gibson CM, Antman EM; TRITON-TIMI 38 Investigators: Prasugrel versus clopidogrel in patients with acute coronary syndrome. N Engl J Med 2007; 357: 2001-15. Kardiol Pol 2008, 66(2):222-225.

2. Wallentin L, Becker RC, Budaj A, Cannon CP, Emanuelsson H, Held C, Horrow J, Husted S, James S, Katus H, Mahaffey KW, Scirica BM, Skene A, Steg PG, Storey RF, Harrington RA, PLATO Investigators, Freij A, Thorsén M: Ticagrelor versus clopidogrel in patients with acute coronary syndromes. $N$ Engl J Med 2009, 361(11):1045-1057.

3. Gurbel PA, Bliden KP, Butler K, Tantry US, Gesheff T, Wei C, Teng R, Antonino MJ, Patil SB, Karunakaran A, Kereiakes DJ, Parris C, Purdy D, Wilson V, Ledley GS, Storey RF: Randomized double-blind assessment of the ONSET and OFFSET of the antiplatelet effects of ticagrelor versus clopidogrel in patients with stable coronary artery disease: the ONSET/OFFSET study. Circulation 2009, 120(25):2577-2585.

4. van Giezen JJ, Sidaway J, Glaves P, Kirk I, Bjorkman JA: Ticagrelor inhibits adenosine uptake in vitro and enhances adenosine-mediated hyperemia responses in a canine model. J Cardiovasc Pharmacol Ther 2012, 17(2):164-172.

5. Bonello L, Laine M, Kipson N, Mancini J, Helal O, Fromonot J, Gariboldi V, Condo J, Thuny F, Frere C, Camoin-Jau L, Paganelli F, Dignat-George F, Guieu R: Ticagrelor increases adenosine plasma concentration in patients with an acute coronary syndrome. J Am Coll Cardiol 2014, 63(9):872-877.

6. Reffelmann T, Kloner RA: Microvascular alterations after temporary coronary artery occlusion: the no-reflow phenomenon. J Cardiovasc Pharmacol Ther 2004, 9(3):163-172.

7. Reffelmann T, Kloner RA: The no-reflow phenomenon: A basic mechanism of myocardial ischemia and reperfusion. Basic Res Cardiol 2006, 101(5):359-372.

8. Kunichika H, Ben-Yehuda O, Lafitte S, Kunichika N, Peters B, DeMaria AN: Effects of glycoprotein Ilb/llla inhibition on microvascular flow after coronary reperfusion. A quantitative myocardial contrast echocardiography study. J Am Coll Cardiol 2004, 43(2):276-283.

9. de Lemos JA, Antman EM, Gibson CM, McCabe CH, Giugliano RP, Murphy SA, Coulter SA, Anderson K, Scherer J, Frey MJ, Van der Wieken R, Van de Werf F, Braunwald E: Abciximab improves both epicardial flow and myocardial reperfusion in ST-elevation myocardial infarction. Observations from the TIMI 14 trial. Circulation 2000, 101(3):239-243.

10. Morrow DA, Wiviott SD, White HD, Nicolau JC, Bramucci E, Murphy SA, Bonaca MP, Ruff CT, Scirica BM, McCabe CH, Antman EM, Braunwald E: Effect of the novel thienopyridine prasugrel compared with clopidogrel on spontaneous and procedural myocardial infarction in the Trial to Assess Improvement in Therapeutic Outcomes by Optimizing Platelet Inhibition with Prasugrel-Thrombolysis in Myocardial Infarction 38: an application of the classification system from the universal definition of myocardial infarction. Circulation 2009, 119(21):2758-2764.

11. Fearon WF, Shah M, Ng M, Brinton T, Wilson A, Tremmel JA, Schnittger I, Lee DP, Vagelos RH, Fitzgerald PJ, Yock PG, Yeung AC: Predictive value of the index of microcirculatory resistance in patients with ST-segment elevation myocardial infarction. J Am Coll Cardiol 2008, 51(5):560-565.

12. McGeoch R, Watkins S, Berry C, Steedman T, Davie A, Byrne J, Hillis S, Lindsay M, Robb S, Dargie H, Oldroyd K: The index of microcirculatory resistance measured acutely predicts the extent and severity of myocardial infarction in patients with ST-segment elevation myocardial infarction. J Am Coll Cardiol Intv 2010, 3(7):715-722.

13. Fearon WF, Balsam LB, Farouque HM, Caffarelli AD, Robbins RC, Fitzgerald $P J$, Yock PG, Yeung AC: Novel index for invasively assessing the coronary microcirculation. Circulation 2003, 107(25):3129-3132.

14. Fearon WF, Nakamura M, Lee DP, Rezaee $M$, Vagelos RH, Hunt SA, Fitzgerald PJ, Yock PG, Yeung AC: Simultaneous assessment of fractional and coronary flow reserves in cardiac transplant recipients: Physiologic Investigation for Transplant Arteriopathy (PITA Study). Circulation 2003, 108(13):1605-1610.

15. Ng MK, Yeung AC, Fearon WF: Invasive assessment of the coronary microcirculation: superior reproducibility and less hemodynamic dependence of index of microcirculatory resistance compared with coronary flow reserve. Circulation 2006, 113(17):2054-2061.

16. Yong AS, Ho M, Shah MG, Ng MK, Fearon WF: Coronary microcirculatory resistance is independent of epicardial stenosis. Circ Cardiovasc Interv 2012, 5(1):103-108. S1-S2.

17. Verhoeff BJ, van de Hoef TP, Spaan JA, Piek JJ, Siebes M: Minimal effect of collateral flow on coronary microvascular resistance in the presence of intermediate and noncritical coronary stenoses. Am J Physiol Heart Circ Physiol 2012, 303(4):H422-H428.

18. Layland J, Carrick D, McEntegart M, Ahmed N, Payne A, McClure J, Sood A, McGeoch R, Maclsaac A, Whitbourn R, Wilson A, Oldroyd K, Berry C: Vasodilatory capacity of the coronary microcirculation is preserved in selected patients with non-ST-segment-elevation myocardial infarction. Circ Cardiovasc Interv 2013, 6(3):231-236.

19. Fearon WF, Low AF, Yong AS, McGeoch R, Berry C, Shah MG, Ho MY, Kim HS, Loh JP, Oldroyd KG: Prognostic value of the Index of Microcirculatory Resistance measured after primary percutaneous coronary intervention. Circulation 2013, 127(24):2436-2441.

20. Niccoli G, Burzotta F, Galiuto L, Crea F: Myocardial no-reflow in humans. J Am Coll Cardiol 2009, 54(4):281-292.

21. Lerman A, Holmes DR, Herrmann J, Gersh BJ: Microcirculatory dysfunction in ST-elevation myocardial infarction: cause, consequence, or both? Eur Heart J 2007, 28(7):788-797.

22. Bolognese L, Carrabba N, Parodi G, Santoro GM, Buonamici P, Cerisano G, Antoniucci D: Impact of microvascular dysfunction on left ventricular remodeling and long-term clinical outcome after primary coronary angioplasty for acute myocardial infarction. Circulation 2004, 109(9):1121-1126.

23. Hombach V, Grebe O, Merkle N, Waldenmaier S, Hoher M, Kochs M, Wohrle J, Kestler HA: Sequelae of acute myocardial infarction regarding cardiac structure and function and their prognostic significance as assessed by magnetic resonance imaging. Eur Heart J 2005, 26(6):549-557.

24. Gibson CM, Cannon CP, Murphy SA, Marble SJ, Barron HV, Braunwald E: Relationship of the TIMI myocardial perfusion grades, flow grades, frame count, and percutaneous coronary intervention to long-term outcomes after thrombolytic administration in acute myocardial infarction. Circulation 2002, 105(16):1909-1913.

25. Sardella G, Mancone M, Bucciarelli-Ducci C, Agati L, Scardala R, Carbone I, Francone M, Di Roma A, Benedetti G, Conti G, Fedele F: Thrombus aspiration during primary percutaneous coronary intervention improves myocardial reperfusion and reduces infarct size: the EXPIRA (thrombectomy with export catheter in infarct-related artery during primary percutaneous coronary intervention) prospective, randomized trial. J Am Coll Cardiol 2009, 53(4):309-315.

26. Claeys MJ, Bosmans J, De Ceuninck M, Beunis A, Vergauwen W, Vorlat A, Vrints CJ: Effect of intracoronary adenosine infusion during coronary intervention on myocardial reperfusion injury in patients with acute myocardial infarction. Am J Cardiol 2004, 94(1):9-13.

27. Ross AM, Gibbons RJ, Stone GW, Kloner RA, Alexander RW: A randomized, double-blinded, placebo-controlled multicenter trial of adenosine as an adjunct to reperfusion in the treatment of acute myocardial infarction (AMISTAD-II). J Am Coll Cardiol 2005, 45(11):1775-1780.

28. Tsujita K, Shimomura H, Kawano H, Hokamaki J, Fukuda M, Yamashita T, Hida S, Nakamura Y, Nagayoshi Y, Sakamoto T, Yoshimura M, Arai H, Ogawa H: Effects of edaravone on reperfusion injury in patients with acute myocardial infarction. Am J Cardiol 2004, 94(4):481-484.

29. Gurbel PA, Bliden KP, Hiatt BL, O'Connor CM: Clopidogrel for coronary stenting: response variability, drug resistance, and the effect of pretreatment platelet reactivity. Circulation 2003, 107(23):2908-2913. 
30. Serebruany VL, Steinhubl SR, Berger PB, Malinin Al, Bhatt DL, Topol EJ: Variability in platelet responsiveness to clopidogrel among 544 individuals. J Am Coll Cardiol 2005, 45(2):246-251.

31. Bonello L, Tantry US, Marcucci R, Blindt R, Angiolillo DJ, Becker R, Bhatt DL, Cattaneo M, Collet JP, Cuisset T, Gachet C, Montalescot G, Jennings LK, Kereiakes D, Sibbing D, Trenk D, Van Werkum JW, Paganelli F, Price MJ, Waksman R, Gurbel PA, Working Group on High On-Treatment Platelet Reactivity: Consensus and future directions on the definition of high on-treatment platelet reactivity to adenosine diphosphate. J Am Coll Cardiol 2010, 56(12):919-933.

32. Shryock JC, Snowdy S, Baraldi PG, Cacciari B, Spalluto G, Monopoli A, Ongini E, Baker SP, Belardinelli L: A2A-adenosine receptor reserve for coronary vasodilation. Circulation 1998, 98(7):711-718.

33. Iwamoto T, Umemura S, Toya Y, Uchibori T, Kogi K, Takagi N, Ishii M: Identification of adenosine A2 receptor-cAMP system in human aortic endothelial cells. Biochem Biophys Res Commun 1994, 199(2):905-910.

34. Cohen MV, Downey JM: Adenosine at reperfusion: a conundrum ready to be resolved. J Am Coll Cardiol 2009, 53(8):718-719.

doi:10.1186/1745-6215-15-151

Cite this article as: Park et al: Comparing the effect of clopidogrel versus ticagrelor on coronary microvascular dysfunction in acute coronary syndrome patients (TIME trial): study protocol for a randomized controlled trial. Trials 2014 15:151.

\section{Submit your next manuscript to BioMed Central and take full advantage of:}

- Convenient online submission

- Thorough peer review

- No space constraints or color figure charges

- Immediate publication on acceptance

- Inclusion in PubMed, CAS, Scopus and Google Scholar

- Research which is freely available for redistribution 